\title{
AVALIAÇÃO DE ÁRVORES DE RISCO NA ARBORIZAÇÃO DE VIAS PÚBLICAS DE NOVA OLÍMPIA, PARANÁ.
}

\author{
André Cesar Furlaneto Sampaio ${ }^{1}$, Felipe Galvão Duarte ${ }^{2}$, Emanuel Giovani Cafofo Silva ${ }^{3}$, Bruno Luiz \\ Domingos De Angelis ${ }^{4}$, Christopher Thomas Blum ${ }^{5}$
}

(recebido em 03.03.2010 e aceito para publicação em 10.06.2010)

\section{RESUMO}

Na região norte e noroeste do Paraná muitas cidades ostentam uma arborização de vias públicas exuberante. Porém, o manejo inadequado, a falta de planejamento e o estresse urbano causam nestas árvores problemas graves ocasionando muitas quedas e grandes prejuízos para a administração pública. Em cidades pequenas, como o caso de Nova Olímpia, o diagnóstico da situação da arborização, assim como o planejamento, podem ser feitos de forma mais rápida e eficiente do que em grandes cidades. $O$ trabalho em questão realizou um inventário (censo) com um sistema de avaliação de parâmetros da copa, do tronco e da base do tronco. Foram analisados o porte das árvores e os riscos para os alvos em caso de queda, assim como, as medições mais usuais. Definiu-se um índice final como forma de hierarquização das árvores com maiores riscos, para assim viabilizar um planejamento mais adequado. Os resultados mostraram árvores com quantidade de problemas mais graves na região do tronco e em sua base. No índice final a maioria das árvores adultas (83,54\%) ficaram como sendo de risco de média importância das quais $14,66 \%$ constaram como em risco de elevada importância necessitando de ações de manejo mais emergenciais.

Palavras-chave: inventário, árvores de risco, avaliação de risco, planejamento da arborização, avaliação por parâmetros.

\footnotetext{
1 Engenheiro Florestal, Doutorando em Geografia - Universidade Estadual de Maringá-PR sampaio.andre@gmail.com

${ }^{2}$ Graduação em Ciências Biológicas, Centro Universitário de Maringá (CESUMAR) bene galvao@hotmail.com

${ }^{3}$ Graduação em Ciências Biológicas, Centro Universitário de Maringá (CESUMAR) emanuelgcs@yahoo.com.br

${ }^{4}$ Professor do Departamento de Agronomia, Universidade Estadual de Maringá (UEM), Maringá, PR - brucagen@uol.com.br

5 Engenheiro Florestal, Doutorando em Engenharia Florestal, UFPR, Curitiba, PR blumct@gmail.com
}

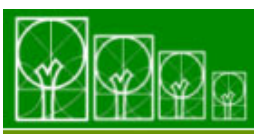

$\mathbf{S} \cdot \mathbf{B} \cdot \mathbf{A} \cdot \mathbf{U}$ Soc. Bras. de Arborização Urbana 


\section{TREE RISK ASSESSMENT IN URBAN FOREST IN PUBLIC STREETS IN NOVA OLIMPIA, PARANÁ}

\section{ABSTRACT}

In north and northwest regions of Paraná State (PR), many cities exhibit exuberant urban forest on public roads. However, inadequate handling, the lack of planning and urban stress cause serious problems to these trees, leading to many falls and great damages to public administration. In small towns, such as Nova Olimpia, the diagnosis of the urban forest situation, as well as the planning, could be done in a much faster and more efficient way than in large cities. This research carried out an inventory with a system of assessment of the parameters of the crown, the trunk and the base of the trunk; analyzing the size of the trees and the risks for targets in case of falls, as well as, most usual dimensions. Defining a final index as a form of creating a hierarchy of the trees that pose the biggest threats, leading thus to a much more adequate planning. The results showed trees with higher serious problems in the trunk and base of the trunk regions. In the final index, the majority of adult trees $(83,54 \%)$ are of medium risk, and $14,66 \%$, a total of 367 trees, are of high risk, demanding emergency interventions.

Keywords: inventory, risk trees, risk assessment, urban forest, parameter assessment 


\section{INTRODUÇÃO}

A cidade de Nova Olímpia, assim como a maioria das cidades do noroeste do Paraná, surgiu do movimento colonizador em busca de terras para o plantio do café. A partir do início do século $\mathrm{XX}$, a ampliação da área cafeeira proporcionou a criação de muitas cidades de leste para oeste, desbravando todo o norte do estado (MONBEIG, 1935). Essas cidades inicialmente se preocuparam com uma inserção rápida e eficiente de árvores em vias públicas, pois o calor e a insolação são bastante acentuados na região. Dessa forma acabaram inserindo uma arborização de vias públicas semelhante entre elas, utilizando-se de mesmas espécies e fazendo plantios em espaçamentos semelhantes, assim como plantando mudas provindas dos mesmos viveiros. Assim, muitas cidades do noroeste paranaense ostentam hoje uma arborização exuberante e bem distribuída.

A problemática encontrada atualmente para estas cidades é que o cuidado com a arborização foi diminuindo, não prevendo um planejamento e manejo adequado das árvores. Com isso, existe um aumento visível da queda de árvores, assim como, uma perda de vitalidade das mesmas, pois grande parte se encontra em idade avançada e sobrecarregada pelo estresse provindo do ambiente urbano (podas constantes, injúrias mecânicas, poluição atmosférica, luz excessiva etc). Segundo Takahashi (1997), a falta de planejamento e replanejamento na arborização de vias públicas é comum nas cidades brasileiras e causa, muitas vezes, sérios prejuízos.

Em cidades de pequeno porte a situação se agrava ${ }_{2}$ pois raramente a administração pública destas cidades conta com profissionais especialistas neste setor, o que colabora em muito para um manejo não adequado de espécies exóticas invasoras, podas drásticas, mudas em péssima qualidade, além de outros vários problemas técnicos.

Contudo, a aplicação de um planejamento e manejo da arborização de vias públicas pode ter uma execução mais eficaz nestes pequenos municípios, já que planejar pequenas áreas é mais fácil, os custos são menores e a mão-de-obra pode ser direcionada e treinada com maior facilidade. A carência na maioria dos casos está no direcionamento de ações, escolha de espécies, aplicação de técnicas, ou seja, realmente no planejamento (SAMPAIO, 2006). A união de estudos científicos e a administração pública de pequenos municípios é crucial na elaboração e manejo da arborização urbana.

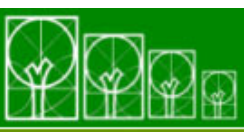

$\mathbf{S} \cdot \mathbf{B} \cdot \mathbf{A} \cdot \mathbf{U}$ Soc. Bras. de Arborização Urbana 
O trabalho em questão visa a realização de um inventário e análise da arborização de vias públicas da cidade de Nova Olímpia, com fim de determinar índices de risco de acidentes e queda dessas árvores, com hierarquização dos resultados para estabelecer as árvores com maiores necessidades de intervenção, ou seja, um subsídio para tomada de decisões em seu manejo.

\section{MATERIAL E MÉTODOS}

\section{Descrição da área de estudo}

O município de Nova Olímpia situa-se entre as coordenadas geográficas 2328'19" sul e 530ㅗ'19" oeste, estando a uma altitude de 438 metros. Possui um área de 134,39 $\mathrm{Km}^{2}$ e sua população estimada em 2007 foi de 5.227 habitantes (IBGE, 2007).

O clima, segundo a classificação de Köppen (1978) é do tipo subtropical Cfa, com verões quentes, geadas pouco freqüentes e chuvas abundantes no verão.

De acordo com o delineamento de Maack (1968) e adotando o Sistema FisionômicoEcológico de Classificação da Vegetação Brasileira, proposto por Veloso e Góes-Filho (1982), o município de Nova Olímpia enquadra-se na região fitogeográfica denominada de Floresta Estacional Semidecidual.

A formação geológica desta área se deu na Era Mesozóica por grandes derrames vulcânicos de lavas denominadas basaltos, que foram recobertas por arenitos e sítios denominadas Arenito Caiuá. Os solos provindos destes sítios apresentam textura média a arenosa, são extremamente friáveis e, conseqüentemente, na maioria dos casos, com alta suscetibilidade à erosão. Os teores de areia atingem $85 \%$ a $90 \%$ e possuem níveis críticos de fósforo, potássio, cálcio, magnésio e, não raro, baixos níveis de matéria orgânica com frequente ocorrência de deficiência de macro e micronutrientes nas culturas (FONSECA e CZUY, 2005).

\section{Delineamento do estudo}

Buscando-se uma compreensão mais detalhada sobre a arborização de vias públicas de Nova Olímpia e do risco de queda das árvores, desenvolveu-se a presente metodologia objetivando quantificar os riscos de queda de todas as árvores do acompanhamento viário da cidade.

A elaboração do inventário realizado nas árvores de vias públicas de Nova Olímpia partiu de uma base cartográfica digitalizada do município, atualizada e fornecida pela

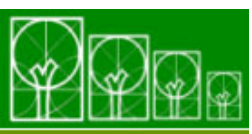

$\mathbf{S} \cdot \mathbf{B} \cdot \mathbf{A} \cdot \mathbf{U}$ Soc. Bras. de Arborização Urbana 
Prefeitura Municipal local, em formato digital (DWG e DXF), contendo os logradouros e lotes de toda a cidade. Utilizando-se da base cartográfica foram delimitados os setores a serem trabalhados no inventário. A cidade foi subdividida em 14 zonas ou setores.

As árvores de vias públicas da cidade foram cadastradas seguindo uma metodologia de registro e avaliação das árvores (SEITZ, 2006). As árvores foram locadas em mapa pelas equipes de campo, através de visualização em campo. O índice de risco foi definido por vários aspectos analisados na copa, tronco, base do tronco e porte das árvores, que na seqüência serão elucidados e descritos. As árvores de risco foram definidas como aquelas que apresentaram defeitos estruturais com probabilidade de causar acidentes por quebra de partes ou de toda a árvore.

Foi considerado que a quebra ou queda das árvores pode ser causada por ventos fortes, desenraizamento, por ação da chuva prolongada (umedecimento excessivo do solo), meio de enraizamento deficiente, podas mal executadas ou em função de colisão de veículos.

Ficou determinado que o risco em um acidente com árvores é potencializado pelo que será atingido na queda, sendo o maior grau de risco atribuído quando existia probabilidade de pessoas serem atingidas. Quando o risco de dano foi julgado como apenas material, este foi considerado menor. $O$ dano material foi relativamente reduzido, porém as conseqüências deste quando incidiam diretamente sobre pessoas ampliaram seu grau de risco final.

A metodologia aplicada considerou que os acidentes com árvores não ocorrem aleatoriamente, eles são resultado da combinação de deficiências estruturais da árvore com fatores ambientais externos que agravam a situação. A sanidade da árvore e o risco de queda não foram determinados como sinônimos na aplicação das avaliações, pois uma árvore pode ser saudável, vigorosa, e mesmo assim provocar acidentes (p.ex., a quebra de um galho seco acima da rede).

As avaliações de cada árvore foram realizadas principalmente através de visualização, sem utilização de instrumentos sofisticados ou técnicas invasivas. Como as avaliações foram feitas através de observações de aspectos muitas vezes subjetivos (análises visuais dos aspectos analisados), podemos considerar que existiu probabilidade de erros humanos na avaliação, porém isso ficou reduzido pela a aplicação de treinamentos específicos para padronização das observações.

\section{Sistema de avaliação}

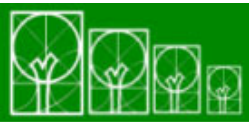

S $\cdot \mathbf{B} \cdot \mathbf{A} \cdot \mathbf{U}$ Soc. Bras. de Arborização Urbana

REVSBAU, Piracicaba - SP, v.5, n.2, p.82-104, 2010 
Objetivando-se executar um método de avaliação por pontuação de variáveis foram analisados vários itens por árvore, que representaram a localização, porte e avaliação das condições gerais da árvore. $\mathrm{Na}$ avaliação das condições gerais das árvores foram observados principalmente problemas no estado fitossanitário. Abaixo está a descrição dos pormenores executados para as análises em questão.

Primeiramente se cadastrou dados de identificação, localização e porte das árvores, que foram usuais para a caracterização básica das árvores analisadas:

\section{Localização}

- Número da árvore (NA) - para a locação das árvores os avaliadores contaram com mapas da cidade nas escalas de 1/1450, 1/1000 e 1/1600 contendo a área total ou parcial de abrangência da avaliação. Nestes mapas foram locadas todas as árvores avaliadas.

Cada árvore ou registro avaliado recebeu um código identificador que foi determinado através da numeração da zona, quadra, lote e sequencial de 1 até $20 . \mathrm{Na}$ ausência de números de quadra, lote ou ambos, foram feitas adequações com os dados contidos no mapa. O código de uma árvore para exemplificar ficaria da seguinte forma: Z01Q001L001A01, demonstrando ser uma árvore da zona1, quadra 001, lote 001 e sendo a primeira árvore em frente ao referido imóvel:

- Logradouro (Via) - Nome da rua, avenida, praça, etc.

- Número do imóvel (NI) - Número do imóvel em frente ao registro cadastrado;

\section{Identificação}

-Tipo de registro (status) - os tipos de registros foram separados nas seguintes categorias:

* Árvore Adulta - foram consideradas as árvores com mais de 3 metros de altura, pois levou-se em conta que as árvores de vias públicas com este porte já estão bem adaptadas ao ambiente urbano, uma vez que estas normalmente são plantadas com mais de 1,5 metros;

* árvore Jovem (muda) - foram consideradas as árvores menores que 3 metros de altura;

* toco - parte restante da base do tronco de uma árvore que foi retirada;

* morta - árvore seca, sem brotações, com ausência de vida; 
* área livre - área das calçadas sem impermeabilização, onde provavelmente existiu uma árvore, mas não se encontra o toco.

-Espécie - dado coletado quando o tipo de registro era referente a árvores adultas ou jovens. Foram identificadas as espécies arbóreas com seus nomes populares, científicos e origens.

-Espaçamento (E) - Medida entre árvores ou tipo de registros.

\section{Porte}

- Altura Total (H) - Foi estimada através de comparação com estruturas urbanas como postes, carros e prédios.

- Altura da Primeira Bifurcação (Hb) - Altura medida com trena do solo até a primeira bifurcação ou galho.

- Circunferência a Altura do Peito (CAP) - Em cada árvore avaliada foi medida a circunferência à altura do peito $(1,3 \mathrm{~m}$ de altura) e no processamento dos dados foi calculado o diâmetro à altura do peito. Nos casos de troncos múltiplos e bifurcados abaixo de 1,3 metros, todos os troncos foram medidos. As medições foram feitas com fitas métricas.

\section{Avaliação das Condições Gerais por Árvore}

Para avaliação das condições gerais das árvores e riscos de queda foram avaliados vários aspectos na copa, no tronco e na base do tronco. Foram selecionados vários aspectos (parâmetros) que na seqüência serão demonstrados, e esses receberam pontuações (grau de risco), que foram registradas em fichas de cadastro divididas por árvores avaliadas. A metodologia em questão foi elaborada através de adaptações na metodologia elaborada pelo Professor Dr. Rudi Arno Seitz (Universidade Federal do Paraná) e descrita em mini-curso no X Congresso Brasileiro de Arborização Urbana, que ocorreu em Maringá-PR, no ano de 2006.

Foi determinado um grau de risco para cada parâmetro avaliado na copa, no tronco e na base do tronco de cada árvore avaliada. Essas pontuações foram feitas considerando uma variação de 0 a 5, sendo 0 para nenhum risco aparente, 1 para riscos pequenos, 2 e 3 para riscos considerados intermediários e 4 e 5 para riscos elevados. Esses graus de riscos foram determinados de acordo com a iminência do acidente e do volume da parte que oferece risco. Um galho seco sem sinais de decomposição, por exemplo, foi classificado com menor grau de risco que um galho com sinais de apodrecimento. Para alguns

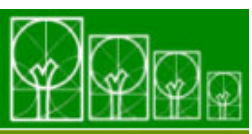

$\mathbf{S} \cdot \mathbf{B} \cdot \mathbf{A} \cdot \mathbf{U}$ Soc. Bras. de Arborização Urbana 
parâmetros não foi possível a implementação dos 5 graus de risco (5 notas), pois a variação da gravidade do risco não permitia, ou seja, os riscos em alguns parâmetros tiveram menos quantidade de notas possíveis.

Ao final da avaliação da árvore a pontuação de interesse para a determinação do índice de risco referente às condições gerais da árvore foi o maior valor encontrado em qualquer dos parâmetros avaliados, pois basta apenas um com grau de risco elevado (potencial de dano) para um dano sério.

\section{Avaliação da copa}

Todas as avaliações foram feitas analisando os parâmetros de forma visual (Tabela 1).

TABELA 1 - Metodologia para avaliação de riscos em parâmetros nas copas das árvores adultas de vias públicas da cidade de Nova Olímpia, PR.

\begin{tabular}{|c|c|c|}
\hline Parâmetro & Definição e justificativa da análise & Metodologia de análise \\
\hline $\begin{array}{l}\text { Galhos } \\
\text { interferindo na } \\
\text { rede }\end{array}$ & $\begin{array}{l}\text { Galhos quando se encostam em redes } \\
\text { elétricas podem causar descargas elétricas } \\
\text { prejudicando árvores e a distribuição de } \\
\text { energia elétrica (SEITZ, 2006). }\end{array}$ & $\begin{array}{c}\text { Risco (nota) } 0 \text { - quando não } \\
\text { existirem galhos em contato com a } \\
\text { rede elétrica. } \\
\text { Risco (nota) } 1 \text { - quando galhos estão } \\
\text { em contato com a rede de baixa } \\
\text { tensão. } \\
\text { Risco (nota) } 5 \text { - quando galhos estão }\end{array}$ \\
\hline
\end{tabular}

Risco (nota) 5 - quando galhos estão em contato com a rede de média ou alta tensão.

\begin{tabular}{|c|c|c|}
\hline $\begin{array}{l}\text { Galhos secos } \\
\text { (podres) }\end{array}$ & $\begin{array}{c}\text { A presença desses galhos indica matéria em } \\
\text { decomposição e problemas fitossanitários. } \\
\text { Atraem fungos e cupins e demonstram a } \\
\text { necessidade de poda de limpeza. A queda } \\
\text { desses galhos pode provocar acidentes } \\
\text { (SEITZ, 2006). }\end{array}$ & $\begin{array}{c}\text { Risco } 0 \text { - quando não existirem } \\
\text { galhos secos ou podres. } \\
\text { Risco } 1 \text { - presença de galhos finos } \\
\text { secos }(<5 \mathrm{~cm} \varnothing) \text {. } \\
\text { Risco } 2 \text { - presença de galhos secos } \\
\text { com diâmetro entre } 5 \text { até } 10 \mathrm{~cm} \text {. } \\
\text { Risco } 3 \text { - presença de galhos secos } \\
\text { com diâmetro em torno entre mais } \\
\text { que } 10 \text { até } 15 \mathrm{~cm} \text {. } \\
\text { Risco } 4 \text { - presença de galhos secos } \\
\text { com diâmetro entre mais que } 15 \mathrm{~cm} \\
\text { até } 20 \mathrm{~cm} \text {. } \\
\text { Risco } 5 \text { - presença de galhos secos } \\
\text { com diâmetro maior que } 20 \mathrm{~cm} \text {. }\end{array}$ \\
\hline Galhos angulados & $\begin{array}{l}\text { São galhos que apresentam angulação } \\
\text { pronunciada, principalmente no sentido } \\
\text { vertical. Estes galhos têm potencial de ruptura } \\
\text { longitudinal, com posterior quebra, podendo } \\
\text { ocasionar acidentes (SEITZ, 2006). }\end{array}$ & $\begin{array}{c}\text { Risco } 0 \text { - quando não existirem } \\
\text { galhos angulados. } \\
\text { Risco 1- presença de galhos finos } \\
\text { angulados }(<5 \mathrm{~cm} \varnothing) . \\
\text { Risco } 2 \text { - galhos angulados com } \varnothing \\
\text { entre } 5 \text { e } 10 \mathrm{~cm} \text {. } \\
\text { Risco } 3 \text { - galhos angulados com } \varnothing \\
\text { entre } 10 \text { e } 15 \mathrm{~cm} \text {. } \\
\text { Risco } 4 \text { - galhos angulados com } \varnothing \\
\text { entre } 15 \text { e } 20 \mathrm{~cm} \text {. } \\
\text { Risco } 5 \text { - presença de galhos } \\
\text { angulados com } \varnothing \text { maior que } 20 \mathrm{~cm} \text {. }\end{array}$ \\
\hline Gall & $\begin{array}{c}\text { São galhos que apresentam folhagem apenas } \\
\text { na extremidade. Podas mal executadas }\end{array}$ & $\begin{array}{c}\text { Risco } 0 \text { - quando não existirem } \\
\text { galhos esguios }\end{array}$ \\
\hline
\end{tabular}




\begin{tabular}{cc}
\hline Parâmetro & Definição e justificativa da análise \\
\hline & $\begin{array}{c}\text { podem levar a formação desses galhos. São } \\
\text { galhos flexíveis que podem vir a quebrar e } \\
\text { causar vários acidentes (SEITZ, 2006). }\end{array}$ \\
& \\
\hline $\begin{array}{c}\text { Lesões na casca } \\
\text { de galhos da } \\
\text { copa }\end{array}$ & Lesões na casca de galhos podem ser \\
provocadas principalmente por \\
descascamentos e queimadas e indicam \\
fragilidade. Para a análise foi julgada a \\
extensão e distribuição da lesão no perímetro \\
do galho, assim como, o tamanho e \\
importância do galho (SEITZ, 2006).
\end{tabular}

\section{Metodologia de análise}

Risco 1- presença de galhos esguios < que $1 \mathrm{~m}$ de comprimento. Risco 2 - galhos esguios com comprimento em torno de $2 \mathrm{~m}$. Risco 3-galhos esguios com comprimento em torno de $3 \mathrm{~m}$. Risco 4-galhos esguios com comprimento em torno de $4 \mathrm{~m}$. Risco 5-galhos esguios com comprimento acima de $4 \mathrm{~m}$.

Risco 0 - quando não existirem lesões nos galhos.

Risco 1- presença de galhos com $\varnothing$

$<10 \mathrm{~cm}$ e com lesões < que $1 / 4$, do perímetro em galhos.

Risco 2- presença de galhos com $\varnothing$

$<10 \mathrm{~cm}$ e com lesões > que $1 / 4$,do perímetro em galhos.

Risco 3- presença de galhos com $\varnothing$ em torno de $15 \mathrm{~cm}$ e com lesões < que $1 / 4$,do perímetro em galhos.

Risco 4- presença de galhos com $\varnothing$ em torno de $15 \mathrm{~cm}$ e com lesões > que $1 / 4$,do perímetro em galhos.

Risco 5- presença de galhos com $\varnothing$

$>15 \mathrm{~cm}$ e com lesões > que $1 / 4$, do perímetro em galhos.

Risco 0 - quando não existirem fungos nos galhos.

Risco 5 - quando existir fungo nos galhos. organismos simples, isto é, com o corpo formado tão somente de um talo uni ou pluricelular, e heterotróficos. São incapazes de criar matéria orgânica a partir dos materiais inorgânicos, ou seja, dependem para sua nutrição, direta ou indiretamente, dos alimentos elaborados pelas plantas. A presença de fungos indica decomposição de matéria orgânica (apodrecimento da madeira). O grau de apodrecimento por visualização é de difícil mensuração (SEITZ, 2006).

Insetos Orifícios de insetos em galhos indicam a Perfuradores presença de prováveis pragas que deterioram a madeira (SEITZ, 2006).
Risco 0 - quando não existirem orifícios de insetos nos galhos. Risco 1- existência de orifícios englobando até $10 \%$ dos galhos da copa.

Risco 2- existência de orifícios englobando cerca de $20 \%$ dos galhos da copa.

Risco 3- existência de orifícios englobando cerca de $30 \%$ dos galhos da copa.

Risco 4- existência de orifícios englobando cerca de $40 \%$ dos galhos da copa.

Risco 5- existência de orifícios englobando cerca de $50 \%$ ou mais dos galhos da copa, ou presentes em galhos grossos $(\varnothing>15 \mathrm{~cm})$ Risco 0 - quando não existirem ervas-de-passarinho.

Risco 1- existência de ervas-depassarinho A erva-de-passarinho é uma planta superior, parasita (Struthantus flexicaulis), que ataca 


\begin{tabular}{|c|c|c|}
\hline Parâmetro & Definição e justificativa da análise & Metodologia de análise \\
\hline & $\begin{array}{c}\text { geralmente as plantas lenhosas e as árvores, } \\
\text { sugando sua seiva e podendo causar até sua } \\
\text { morte se não for retirada. A parasita recebeu } \\
\text { esse nome porque se espalha com a ajuda de } \\
\text { pássaro que ingerem as sementes, mais tarde } \\
\text { eliminadas junto com as fezes. Estabelece-se } \\
\text { principalmente na copa de árvores. Quando } \\
\text { verificadas devem ser retiradas dos galhos } \\
\text { através de poda_(SEITZ, 2006). }\end{array}$ & $\begin{array}{l}\text { passarinho englobando até } 10 \% \text { dos } \\
\text { galhos da copa. } \\
\text { Risco 2- existência de ervas-de- } \\
\text { passarinho englobando cerca de } \\
20 \% \text { dos galhos da copa. } \\
\text { Risco 3- existência de ervas-de- } \\
\text { passarinho englobando cerca de } \\
30 \% \text { dos galhos da copa. } \\
\text { Risco 4- existência de ervas-de- } \\
\text { passarinho englobando cerca de } \\
40 \% \text { dos galhos da copa. } \\
\text { Risco 5- existência de ervas-de- } \\
\text { passarinho englobando cerca de } \\
50 \% \text { ou mais dos galhos da copa }\end{array}$ \\
\hline $\begin{array}{c}\text { Folhagem rala / } \\
\text { Coloração / } \\
\text { Quantidade e } \\
\text { tamanho de } \\
\text { folhas }\end{array}$ & $\begin{array}{c}\text { Cada espécie arbórea tem um padrão de cor } \\
\text { da folhagem, que pode variar durante o } \\
\text { período vegetativo. Em condições de estresse } \\
\text { as árvores tendem a produzir menos folhas, } \\
\text { variar o tamanho das folhas ou às vezes variar } \\
\text { a coloração demonstrando mais pálidez. Foi } \\
\text { avaliado, pois é um indicativo de problemas no } \\
\text { enraizamento das árvores ou outros distúrbios } \\
\text { que afetam a fisiologia da árvore (SEITZ, } \\
\text { 2006). }\end{array}$ & $\begin{array}{c}\text { Risco } 0 \text { - quando não existirem } \\
\text { problemas evidentes na folhagem. } \\
\text { Risco 1- existência de problemas na } \\
\text { folhagem englobando até } 10 \% \text { dos } \\
\text { galhos da copa. } \\
\text { Risco 2- existência de problemas na } \\
\text { folhagem englobando cerca de } 20 \% \\
\text { dos galhos da copa. } \\
\text { Risco 3- existência de problemas na } \\
\text { folhagem englobando cerca de } 30 \% \\
\text { dos galhos da copa. } \\
\text { Risco 4- existência de problemas na } \\
\text { folhagem englobando cerca de } 30 \% \\
\text { dos galhos da copa. } \\
\text { Risco 5- existência de problemas na } \\
\text { folhagem englobando } 50 \% \text { ou mais } \\
\text { dos galhos da copa. }\end{array}$ \\
\hline $\begin{array}{l}\text { Poda unilateral e } \\
\text { drástica }\end{array}$ & $\begin{array}{c}\text { Poda unilateral é aquela que se retira em } \\
\text { demasia apenas um setor da copa. Poda } \\
\text { drástica é aquela em que se deixa a copa com } \\
\text { poucos galhos ou nenhum. Essas podas } \\
\text { influem diretamente nas condições do } \\
\text { enraizamento, pois a retirada de galhos } \\
\text { estabelece menor exigência nutricional e } \\
\text { fisiológica causando morte de raízes já bem } \\
\text { estabelecidas. Provocam desequilíbrio na } \\
\text { árvore ocasionando maior potencial de queda } \\
\text { (SEITZ, 2006). }\end{array}$ & $\begin{array}{l}\text { Risco } 0 \text { - quando não existir poda } \\
\text { unilateral ou drástica. } \\
\text { Risco } 4-\text { existência de poda } \\
\text { unilateral. Poda causando } \\
\text { desequilíbrio nítido na árvore, com } \\
\text { retirada de apenas um setor da } \\
\text { poda. Considera-se até } 50 \% \text { de } \\
\text { retirada dos galhos da copa. } \\
\text { Risco 5- existência de poda drástica, } \\
\text { considerando mais de } 50 \% \text { dos } \\
\text { galhos da copa retirados. }\end{array}$ \\
\hline
\end{tabular}

\section{Avaliação do tronco}

Todas as avaliações foram feitas através de análise visual e algumas com a utilização de equipamentos simples (Tabela 2).

TABELA 2 - Metodologia para avaliação de riscos em parâmetros nos troncos das árvores adultas de vias públicas da cidade de Nova Olímpia, PR.

\begin{tabular}{ccc}
\hline Parâmetro & Definição e justificativa da análise & Metodologia de análise \\
\hline $\begin{array}{c}\text { Invasão da pista } \\
\text { (inclinação do } \\
\text { tronco) }\end{array}$ & $\begin{array}{c}\text { Verificaram-se os troncos inclinados } \\
\text { invadindo o espaço sobre a via de rolamento, } \\
\text { dificultando a passagem de pedestres (SEITZ, } \\
\text { 2006). Com ajuda de um clinômetro verificou- } \\
\text { se a inclinação dos troncos invadindo o }\end{array}$ & $\begin{array}{c}\text { Risco 0- para troncos sem } \\
\text { inclinação para o lado do }\end{array}$ \\
$\begin{array}{c}\text { calçamento. } \\
\text { Risco 1- tronco com inclinação } \\
\text { menor que 10\%. }\end{array}$ \\
\begin{tabular}{c} 
Risco 2- tronco com inclinação entre \\
\hline
\end{tabular}
\end{tabular}




\begin{tabular}{|c|c|c|}
\hline Parâmetro & Definição e justificativa da análise & Metodologia de análise \\
\hline & calçamento. & $\begin{array}{c}10^{\circ} \text { e } 20^{\circ} . \\
\text { Risco 3- tronco com inclinação entre } \\
\text { mais que } 20^{\circ} \text { e } 30^{\circ} \text {. } \\
\text { Risco 4- tronco com inclinação entre } \\
>30^{\circ} \text { até } 40^{\circ} \text {. } \\
\text { Risco 5- tronco com inclinação de } \\
50^{\circ} \text { ou mais. }\end{array}$ \\
\hline Cavidades & $\begin{array}{c}\text { Cavidades no tronco indicam deterioração da } \\
\text { madeira com prejuízos nas funções } \\
\text { fisiológicas da árvore. O tamanho e extensão } \\
\text { da cavidade influem no risco para a árvore. } \\
\text { Quanto maior a extensão e o tamanho maior o } \\
\text { risco de uma queda futura. } \\
\text { Foi considerado apenas o comprometimento } \\
\text { visível na árvore. Muitas vezes o restante do } \\
\text { interior do tronco, além da cavidade, também } \\
\text { está comprometido, entretanto esta } \\
\text { possibilidade não pôde ser verificada, pois não } \\
\text { se possuíam os equipamentos necessários } \\
\text { (SEITZ, 2006). }\end{array}$ & $\begin{array}{c}\text { Risco } 0 \text { - quando não existir } \\
\text { cavidade no tronco. } \\
\text { Risco 1- cavidade (oco) } \\
\text { comprometendo menos que } 50 \% \text { da } \\
\text { área transversal do tronco. } \\
\text { Risco } 3 \text { - cavidade (oco) } \\
\text { comprometendo entre } 50 \% \text { até } 70 \% \\
\text { da área transversal do tronco. } \\
\text { Risco } 5 \text { - cavidade (oco) } \\
\text { comprometendo mais de } 70 \% \text { da } \\
\text { área transversal do tronco. }\end{array}$ \\
\hline $\begin{array}{c}\text { Lesões e aspecto } \\
\text { da casca }\end{array}$ & $\begin{array}{l}\text { As lesões nas cascas de árvores não são } \\
\text { motivos diretamente relacionados à queda de } \\
\text { árvores, porém, dependendo do perímetro do } \\
\text { tronco afetado, isto pode levar a uma } \\
\text { debilidade do sistema radicial, colaborando } \\
\text { para uma futura queda (SEITZ, 2006). }\end{array}$ & $\begin{array}{c}\text { Risco } 0 \text { - quando não existirem } \\
\text { lesões na casca. } \\
\text { Risco } 1 \text { - presença de lesões } \\
\text { englobando menos que } 25 \% \text {, do } \\
\text { perímetro do tronco. } \\
\text { Risco } 2 \text { - presença de lesões } \\
\text { englobando de } 25 \% \text { até } 50 \% \text { do } \\
\text { perímetro do tronco. } \\
\text { Risco 3- presença de lesões } \\
\text { englobando entre mais de } 50 \% \text { até } \\
75 \% \text { do perímetro do tronco. } \\
\text { Risco } 4-\text { presença de lesões maiores } \\
\text { que } 75 \% \text { do perímetro do tronco. } \\
\text { Risco } 2 \text { - presença de lesões } \\
\text { profunda e maior que } 75 \% \text { do } \\
\text { perímetro do tronco. }\end{array}$ \\
\hline $\begin{array}{c}\text { Orifícios de } \\
\text { insetos (cupim) }\end{array}$ & $\begin{array}{c}\text { Considerou-se que a presença de insetos } \\
\text { indica condições ruins para a árvore, embora } \\
\text { nem sempre isto signifique um risco elevado } \\
\text { de queda (SEITZ, 2006). Observou-se orifícios } \\
\text { de eclosão, de respiração e eliminação de } \\
\text { resíduos, pela serragem acumulada na base } \\
\text { ou ainda por gotas ou exsudação de gomas ou } \\
\text { resinas. Os cupins foram verificados através } \\
\text { de ninhos arborícolas (copa) e trilhas feitas por } \\
\text { estes no tronco. }\end{array}$ & $\begin{array}{c}\text { Risco } 0 \text { - quando não existirem } \\
\text { vestígios de insetos. } \\
\text { Risco } 1 \text { - presença de orifícios } \\
\text { englobando menos de } 10 \% \text { da área } \\
\text { do tronco. } \\
\text { Risco } 2 \text { - presença de orifícios } \\
\text { englobando entre } 10 \% \text { até } 20 \% \text { da } \\
\text { área do tronco. } \\
\text { Risco 3- presença de orifícios } \\
\text { englobando entre mais de } 20 \% \text { até } \\
30 \% \text { da área do tronco. } \\
\text { Risco } 4 \text { - presença de orifícios } \\
\text { englobando entre mais } 30 \% \text { até } 40 \% \\
\text { da área do tronco. } \\
\text { Risco } 5 \text { - presença de orifícios } \\
\text { englobando mais de } 50 \% \text { da área do } \\
\text { tronco ou com presença de cupins. }\end{array}$ \\
\hline Fungos & $\begin{array}{c}\text { A presença de fungos indica decomposição de } \\
\text { matéria orgânica (apodrecimento da madeira). } \\
\text { O grau de apodrecimento por visualização é } \\
\text { de difícil mensuração (SEITZ, 2006). }\end{array}$ & $\begin{array}{l}\text { Risco } 0 \text { - quando não existir fungos } \\
\text { no tronco. } \\
\text { Risco } 5 \text { - quando existir fungos no } \\
\text { tronco. }\end{array}$ \\
\hline Cancro & $\begin{array}{l}\text { O cancro pode ser definido como um sintoma } \\
\text { associado à presença de fungos (Sphaeropsis }\end{array}$ & $\begin{array}{l}\text { Risco } 0 \text { - quando não existirem } \\
\text { cancros no tronco. }\end{array}$ \\
\hline
\end{tabular}




\begin{tabular}{|c|c|c|}
\hline Parâmetro & Definição e justificativa da análise & Metodologia de análise \\
\hline & $\begin{array}{c}\text { sapinea, Phytophthora spp., Cryphonectria } \\
\text { cubensis, Valsa ceratosperma, Botryospheria } \\
\text { e outros), normalmente se apresenta como } \\
\text { uma lesão margeada de calos, com a morte } \\
\text { do câmbio e de parte da circunferência do } \\
\text { tronco (CASTRO, 2004). Utilizou-se como } \\
\text { referência o trabalho de Castro (2004) para a } \\
\text { determinação dos riscos. }\end{array}$ & $\begin{array}{c}\text { Risco } 1 \text { - existência de cancro com } \\
\text { área entorno de } 200 \mathrm{~cm}^{2} \text {. } \\
\text { Risco } 2 \text { - cancro com área maior que } \\
200 \mathrm{~cm}^{2} \text { até } 1000 \mathrm{~cm}^{2} \text {. } \\
\text { Risco } 3-\mathrm{cancro}^{2} \text { com área maior que } \\
1000 \mathrm{~cm}^{2} \text { até } 5000 \mathrm{~cm}^{2} \text {. } \\
\text { Risco } 4-\text { cancro com área maior que } \\
5000 \mathrm{~cm}^{2} \text { até } 10000 \mathrm{~cm}^{2} \text {. } \\
\text { Risco } 5 \text { - cancro com área maior que } \\
1000 \mathrm{~cm}^{2} \text {, ou com mais de } 50 \% \text { do } \\
\text { tronco atingido }\end{array}$ \\
\hline $\begin{array}{c}\text { Injúrias } \\
\text { mecânicas }\end{array}$ & $\begin{array}{l}\text { Certas injúrias provocadas por vandalismos } \\
\text { nos troncos das árvores podem provocar } \\
\text { danos a saúde da árvore (SEITZ, 2006). }\end{array}$ & $\begin{array}{c}\text { Risco } 0 \text { - quando não existir injúrias. } \\
\text { Risco } 1 \text { - existência de desenhos e } \\
\text { escritos no tronco. } \\
\text { Risco } 2 \text { - existência de ervas-de- } \\
\text { passarinho englobando cerca de } \\
20 \% \text { dos galhos da copa. } \\
\text { Risco 3- existência de ervas-de- } \\
\text { passarinho englobando cerca de } \\
30 \% \text { dos galhos da copa. } \\
\text { Risco 4- existência de ervas-de- } \\
\text { passarinho englobando cerca de } \\
40 \% \text { dos galhos da copa. } \\
\text { Risco 5- existência de ervas-de- } \\
\text { passarinho englobando cerca de } \\
50 \% \text { ou mais dos galhos da copa }\end{array}$ \\
\hline
\end{tabular}

\section{Avaliação da base do tronco}

Esta avaliação foi considerada crucial para avaliação do risco final da árvore, pois a base do tronco e as raízes são fundamentais para a estabilidade da árvore. Em muitos casos, as quedas das árvores estão associadas a danos nas raízes (SEITZ, 2006). Como é difícil avaliar o estado das raízes, utilizam-se indicadores principalmente avaliados na base do tronco. A tabela 3 demonstra a metodologia utilizada por parâmetros avaliados.

TABELA 3 - Metodologia para avaliação de riscos em parâmetros na base dos troncos das árvores adultas de vias públicas da cidade de Nova Olímpia, PR.

\begin{tabular}{|c|c|c|}
\hline Parâmetro & Definição e justificativa da análise & Metodologia de análise \\
\hline $\begin{array}{c}\text { Brotação } \\
\text { epicórmica }\end{array}$ & $\begin{array}{l}\text { São pequenos brotos de raízes localizados na } \\
\text { base do tronco. Indicam deficiência na } \\
\text { circulação da seiva, que acaba por prejudicar } \\
\text { a alimentação das raízes finas, mas que não } \\
\text { oferece risco iminente (SEITZ, 2006). }\end{array}$ & $\begin{array}{l}\text { Risco } 0 \text { - quando não existir } \\
\text { brotação epicórmica. } \\
\text { Risco 1- quando existir brotação } \\
\text { epicórmica. }\end{array}$ \\
\hline $\begin{array}{l}\text { Lesões na base } \\
\text { do tronco }\end{array}$ & $\begin{array}{c}\text { As lesões de árvores não são motivos } \\
\text { diretamente relacionados à queda de árvores, } \\
\text { entretanto dependendo do perímetro do tronco } \\
\text { afetado, pode levar a uma debilidade do } \\
\text { sistema radicial colaborando para uma futura } \\
\text { queda (SEITZ, 2006). }\end{array}$ & $\begin{array}{c}\text { Risco } 0 \text { - quando não existirem } \\
\text { lesões. } \\
\text { Risco } 1 \text { - presença de lesões } \\
\text { englobando menos que } 25 \% \text {, do } \\
\text { perímetro da base do tronco. } \\
\text { Risco } 2 \text { - presença de lesões } \\
\text { englobando de } 25 \% \text { até } 50 \% \text { do } \\
\text { perímetro da base do tronco. } \\
\text { Risco 3- presença de lesões } \\
\text { englobando entre mais de } 50 \% \text { até } \\
75 \% \text { do perímetro da base do tronco. } \\
\text { Risco 4- presença de lesões maiores }\end{array}$ \\
\hline
\end{tabular}




\begin{tabular}{|c|c|c|}
\hline Parâmetro & Definição e justificativa da análise & Metodologia de análise \\
\hline & & $\begin{array}{l}\text { que } 75 \% \text { do perímetro da base do } \\
\text { tronco. } \\
\text { Risco } 2 \text { - presença de lesões } \\
\text { profundas e maiores que } 75 \% \text { do } \\
\text { perímetro da base do tronco. }\end{array}$ \\
\hline $\begin{array}{l}\text { Cavidades na } \\
\text { base do tronco }\end{array}$ & Idem da definição na avaliação do tronco. & $\begin{array}{c}\text { Risco } 0 \text { - quando não existir } \\
\text { cavidade na base do tronco. } \\
\text { Risco } 1 \text { - cavidade (oco) } \\
\text { comprometendo menos que } 50 \% \text { da } \\
\text { área transversal da base do tronco. } \\
\text { Risco } 3 \text { - cavidade (oco) } \\
\text { comprometendo entre } 50 \% \text { até } 70 \% \\
\text { da área transversal da base tronco. } \\
\text { Risco } 5 \text { - cavidade (oco) } \\
\text { comprometendo mais de } 70 \% \text { da } \\
\text { área transversal da base do tronco. }\end{array}$ \\
\hline Fungos & Idem da definição das outras avaliações & $\begin{array}{l}\text { Risco } 0 \text { - quando não existir fungos } \\
\text { na base do tronco. } \\
\text { Risco } 5 \text { - quando existir fungos na } \\
\text { base do tronco. }\end{array}$ \\
\hline $\begin{array}{l}\text { Raízes } \\
\text { Adventícias } \\
\text { aparentes }\end{array}$ & $\begin{array}{c}\text { São todas aquelas que, secundariamente, } \\
\text { independentes da raiz primária do embrião, } \\
\text { nascem nos caules ou nas folhas de qualquer } \\
\text { vegetal. Quando ocorrem em árvores são } \\
\text { indicativo de problemas nas raízes (SEITZ, } \\
\text { 2006). }\end{array}$ & $\begin{array}{c}\text { Risco } 0 \text { - quando não existirem } \\
\text { raízes adventícias. } \\
\text { Risco 1- existência de poucas raízes } \\
\text { concentradas apenas em uma região } \\
\text { da base do tronco. } \\
\text { Risco 2- existência de poucas raízes } \\
\text { espalhadas por todo o perímetro da } \\
\text { base do tronco. } \\
\text { Risco 3- existência de muitas raízes } \\
\text { concentradas apenas em uma região } \\
\text { da base do tronco. } \\
\text { Risco 4- existência de muitas raízes } \\
\text { espalhadas por até } 50 \% \text { do } \\
\text { perímetro da base do tronco. } \\
\text { Risco 5- existência de muitas raízes } \\
\text { espalhadas por todo o perímetro da } \\
\text { base do tronco. }\end{array}$ \\
\hline $\begin{array}{c}\text { Injúrias } \\
\text { mecânicas }\end{array}$ & $\begin{array}{l}\text { Certas injúrias provocadas por vandalismo nos } \\
\text { troncos das árvores podem provocar danos a } \\
\text { saúde da árvore (SEITZ, 2006). }\end{array}$ & $\begin{array}{c}\text { Risco } 0 \text { - quando não existir injúrias. } \\
\text { Risco } 1 \text { - existência de desenhos e } \\
\text { escritos no tronco. } \\
\text { Risco 2- existência de ervas-de- } \\
\text { passarinho englobando cerca de } \\
20 \% \text { dos galhos da copa. } \\
\text { Risco 3- existência de ervas-de- } \\
\text { passarinho englobando cerca de } \\
30 \% \text { dos galhos da copa. } \\
\text { Risco } 4 \text { - existência de ervas-de- } \\
\text { passarinho englobando cerca de } \\
40 \% \text { dos galhos da copa. } \\
\text { Risco 5- existência de ervas-de- } \\
\text { passarinho englobando cerca de } \\
50 \% \text { ou mais dos galhos da copa }\end{array}$ \\
\hline $\begin{array}{l}\text { Espaço } \\
\text { permeável } \\
\text { (Área livre) }\end{array}$ & $\begin{array}{l}\text { As árvores de vias públicas ficam instaladas } \\
\text { em área permeáveis em meio a calçadas. O } \\
\text { tamanho dessas áreas normalmente é } \\
\text { pequeno, não sendo viável para a perfeita } \\
\text { ciclagem de nutrientes e infiltração da água. } \\
\text { Normalmente também contribuí para uma } \\
\text { maior compactação do solo (BIONDI, 1985). } \\
\text { Espaços exíguos podem aumentar o risco de }\end{array}$ & $\begin{array}{c}\text { Risco } 1 \text { - espaço permeável maiores } \\
\text { que } 1,5 \mathrm{~m}^{2} \text {. } \\
\text { Risco } 3 \text { - espaço permeável entre } 1 \\
\text { até } 1,5 \mathrm{~m}^{2} \text {. } \\
\text { Risco } 5 \text { - sem espaço. Tronco } \\
\text { cercado por área impermeável. }\end{array}$ \\
\hline
\end{tabular}




\begin{tabular}{|c|c|c|}
\hline Parâmetro & Definição e justificativa da análise & Metodologia de análise \\
\hline & $\begin{array}{l}\text { queda principalmente por não permitirem uma } \\
\text { expansão adequada das raízes (SEITZ, 2006). }\end{array}$ & \\
\hline $\begin{array}{l}\text { Ausência de } \\
\text { Neilóide }\end{array}$ & $\begin{array}{l}\text { A base da grande maioria das árvores tem } \\
\text { uma forma geométrica denominada neilóide. } \\
\text { Quando esta forma não é identificada, ou seja, } \\
\text { quando a base do tronco apresenta-se muito } \\
\text { cilíndrica, é um indício de aterramento das } \\
\text { mudas no plantio ou posteriormente. Esse } \\
\text { aterramento dificulta trocas gasosas e deixa } \\
\text { as raízes em regiões de solo compactado } \\
\text { (SEITZ, 2006). }\end{array}$ & $\begin{array}{l}\text { Risco } 0 \text { - quando existir neilóide. } \\
\text { Risco } 5 \text { - ausência de neilóide. }\end{array}$ \\
\hline Raízes cortadas & $\begin{array}{l}\text { Controlar o crescimento das raízes através da } \\
\text { poda é uma atividade de risco para o equilíbrio } \\
\text { das árvores urbanas. Diferente da poda de } \\
\text { galhos, normalmente não há acesso ao } \\
\text { sistema radicial em seu todo, para avaliar se } \\
\text { determinada raiz é "supérflua" ou não. } \\
\text { Eventualmente a raiz que está provocando } \\
\text { incômodos é a única que está sustentando a } \\
\text { árvore. Dessa forma toda árvore que teve } \\
\text { suas raízes podadas para se ajustar a } \\
\text { canteiros em calçadas ou em função de } \\
\text { escavações para passagem de tubulação } \\
\text { subterrânea, é uma árvore de risco, pois sua } \\
\text { estabilidade fica comprometida (SEITZ, 2006) }\end{array}$ & $\begin{array}{c}\text { Risco } 0 \text { - quando não existir } \\
\text { evidências de raízes cortadas. } \\
\text { Risco } 1 \text { - evidência de pelo menos } 2 \\
\text { raízes cortadas. } \\
\text { Risco } 3 \text { - evidência de mais de } 2 \\
\text { raízes cortadas em uma região do } \\
\text { tronco. } \\
\text { Risco } 5 \text { - evidência de mais de } 2 \\
\text { raízes cortadas em todo o perímetro } \\
\text { da base do tronco. }\end{array}$ \\
\hline
\end{tabular}

\section{Avaliação do Índice de Risco de Queda}

Considerando que a importância do risco da queda de uma árvore está relacionada ao provável dano causado nesta queda, temos que uma árvore presente em locais muito movimentados ou com estruturas importantes ou frágeis ao seu redor, tem grande potencial de danos. No ambiente urbano a situação de alvos presentes é bastante diversa e com freqüência pode trazer danos materiais ou às pessoas. Foi estabelecido um índice de riscos para alvos referentes às redes elétricas e outro para alvos de efeito colateral.

Pontuação de índice de risco para rede elétrica: foi considerado risco 1 quando as árvores se encontravam em locais sem a rede elétrica, 3 para a rede de baixa tensão e 5 pontos para a rede de média tensão.

Pontuação de índice de risco de efeito colateral: esta avaliação levou em conta principalmente o risco de danos às pessoas. Dessa forma a queda de uma árvore em uma rua movimentada teve maior grau de risco do que a queda de uma árvore em uma área sem residências. Essa avaliação foi chamada de riscos de efeitos colaterais e teve a seguinte determinação: Rua movimentada - risco (nota) 5; rua residencial - risco 3; e rua sem casas - risco 1. 


\section{Avaliação para Hierarquização do Risco de Queda (índice final)}

Através da avaliação das condições gerais de cada árvore e dos riscos para os alvos foi possível determinar um índice para hierarquizar os riscos de queda (índice final), pois no manejo das árvores de vias públicas, nos momentos de tomada de decisão, é importante que se tenha esse embasamento para indicações de remoções e ações corretivas.

Para o estabelecimento desse índice final foi verificado qual o maior valor encontrado nos índices das condições gerais avaliados por árvore. Embora uma árvore possa ter muitas partes que ofereçam risco, a parte que maior risco ofereceu deve ser considerada a mais importante, pois basta apenas um risco sério para este ter grande importância.

O índice final fica determinado através da somatória do maior valor de risco encontrado na avaliação das condições gerais por árvores, com a pontuação dos riscos de alvos (rede elétrica e efeitos colaterais). $O$ índice final de cada árvore variará, portanto, de 3 (pouco risco) a 15 (risco elevado).

Em termos gerais considera-se que:

* Índice de 3 até 6 - risco de menor importância

* Índice de 7 até 11 - risco de média importância

* Índice de 12 até 15 - risco de elevada importância

\section{RESULTADOS E DISCUSSÃO}

\section{Quantidade, distribuição e composição da população amostrada}

Todos os registros da área pesquisada receberam um número identificador e tiveram seus dados cadastrados e analisados (tabela 4).

TABELA 4 - Classificação dos dados cadastrados nas vias públicas e praças da cidade de Nova Olímpia, PR.

\begin{tabular}{ccc}
\hline Status do Registro & Quantidade & Porcentagem (\%) \\
\hline Adultas & 2230 & 64,58 \\
Mudas & 921 & 26,67 \\
Área livre & 52 & 1,50 \\
Tocos & 233 & 6,75 \\
Mortas & 17 & 0,49 \\
\hline TOTAL & $\mathbf{3 4 5 3}$ & $\mathbf{1 0 0 \%}$
\end{tabular}


Conforme os dados apresentados na tabela 4 existem nas vias públicas e praças de Nova Olímpia (área amostrada) um total de $\mathbf{3 1 5 1}$ árvores, sendo o restante, espaços que foram verificados e que indicam locais prováveis para novos plantios.

Em relação à diversidade de espécies (Tabela 5) temos que Caesalpinia peltophoroides (sibipiruna) é a única fora do padrão proposto por Grey e Deneke (1978) que permite uma freqüência de 10 até 15\% em zonas urbanas de uma mesma espécie (Tabela 5). Desta forma o problema da composição florística da arborização de vias públicas de Nova Olímpia, considerando toda a cidade, está focado principalmente nesta espécie. Licania tomentosa (oiti) também teve freqüência bastante elevada, sendo que a continuidade de plantio dessa espécie compromete a estabilização de uma boa composição florística para a cidade.

TABELA 5 - Freqüência em porcentagem (F) das principais espécies encontradas em toda população amostrada.

\begin{tabular}{cccc}
\hline Nome Popular & Nome científico & Q Total & F (\%) \\
\hline Sibipiruna & Caesalpinia peltophoroides Benth. & 1122 & 35,61 \\
Oiti & Licania tomentosa (Thunb.)(Lindl.) & 470 & 14,92 \\
Ficus & Ficus benjamina L. & 175 & 5,55 \\
Ipê-Amarelo & Tabebuia chrysotricha Mart. ex (A. DC.) Standl.) & 151 & 4,79 \\
Palmeira Fenix & Phoenix roebelenii & 133 & 4,22 \\
Palmeira-Imperial & Roystonea oleracea (Jacq.) (O.F. Cook) & 132 & 4,19 \\
Ipê-Roxo & Tabebuia avellanedae Lorentz ex Griseb. & 97 & 3,08 \\
Falsa-Murta & Murraya paniculata L. (Jack) & 91 & 2,89 \\
Chapéu-De-Sol & Terminalia catappa L. & 62 & 1,97 \\
Mangueira & Mangifera indica L. & 57 & 1,81 \\
Castanha-Do-Brejo & Pachira aquatica Aubl. & 43 & 1,36 \\
Ipê-Branco & Tabebuia roseoalba (Ridl.) (Sandwith) & 34 & 1,08 \\
Tuia & Thuja sp & 31 & 0,98 \\
Aroeira-Salsa & Schinus molle L. & 21 & 0,67 \\
Primavera & Bougainvillea glabra Choisy & 20 & 0,63 \\
Alecrim & Holocalyx balansae Micheli & 18 & 0,57 \\
\hline & Total & $\mathbf{2 6 5 7}$ & $\mathbf{8 4 , 3 2}$ \\
\hline
\end{tabular}

Fonte : Resultados Inventário Nova Olímpia-PR

A somatória das frequências das 10 principais espécies correspondem a 79,03\% da população amostrada (Tabela 5). Em Águas de São Pedro, SP, a soma das dez principais espécies perfizeram 48,33\% (BORTOLETO, 2004). Em Jaboticabal, SP, o resultado foi de $71,25 \%$ (SILVA FILHO, 2002). Em Maringá, PR, essa soma foi de 74,76\% (SAMPAIO, 2006). Em Piracicaba, SP, onde o total de espécies foi de apenas 35 espécies, as treze principais somaram $86,5 \%$ da população (LIMA et al.,1994). Nesses casos, a arborização de 
Nova Olímpia se iguala a cidades onde o índice de biodiversidade e a qualidade da arborização não tiveram bons resultados.

\section{Análise dos parâmetros de avaliação para risco na rede elétrica}

Referente ao risco de galhos interferirem na rede elétrica foi verificado que 1323 árvores de Nova Olímpia estão localizadas em locais livres de rede elétrica, 734 estão em baixo de redes de baixa tensão e 173 estão abaixo de redes de média tensão (Figura 1). Dessa forma sabemos que a população de árvores que pode apresentar riscos de ter galhos interferindo na rede é de 907 . As análises demonstradas no gráfico abaixo foram feitas em relação a esta população.

FIGURA 1 - Porcentagem dos índices de riscos de galhos interferindo na rede encontrados nas árvores da população de árvores adultas de Nova Olímpia, PR.

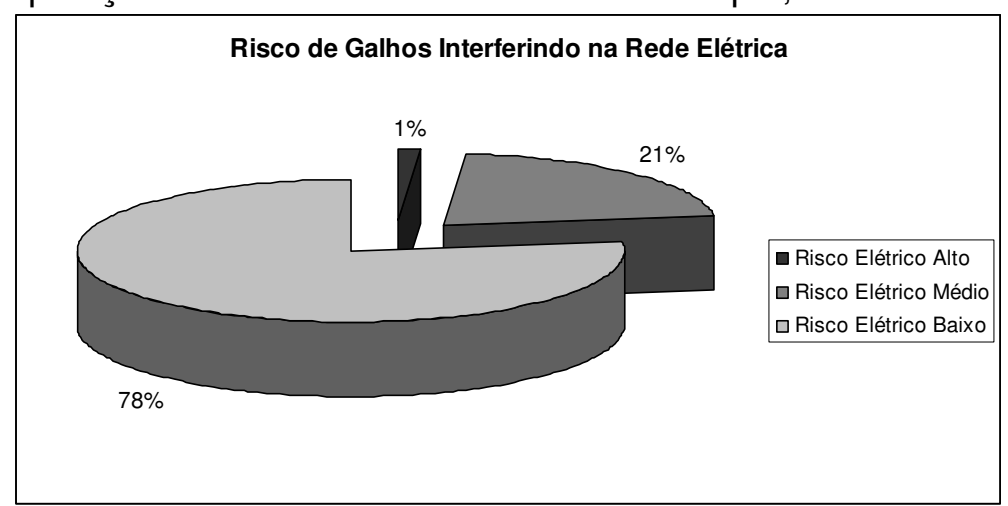

Constatou-se que existem poucas árvores com grau de risco alto em relação ao contato com a rede elétrica, o que é um indicativo que podas de manutenção para afastamento de galhos da rede têm sido efetuadas periodicamente pela companhia responsável (COPEL).

\section{Análise dos parâmetros de avaliação nas regiões da copa, do tronco e na base do} tronco.

A seguir se discutirá os resultados das avaliações de graus de riscos nos vários aspectos observados nas regiões analisadas por árvore (Tabela 6, 7 e 8). As análises foram feitas apenas para os indivíduos adultos, pois esses são os que realmente apresentam maiores possibilidades de danos.

TABELA 6 - Distribuição da avaliação de riscos dos parâmetros avaliados nas copas das árvores adultas de vias públicas da cidade de Nova Olímpia, PR.

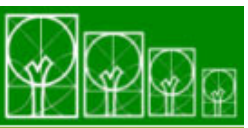




\begin{tabular}{cccccccccc}
\hline $\begin{array}{c}\text { Risco } \\
\text { (nota) }\end{array}$ & $\begin{array}{c}\text { Galhos } \\
\text { secos } \\
\text { (podres) }\end{array}$ & $\begin{array}{c}\text { Galhos } \\
\text { angulados }\end{array}$ & $\begin{array}{c}\text { Lesões } \\
\text { de } \\
\text { casca }\end{array}$ & $\begin{array}{c}\text { Galhos } \\
\text { esguios }\end{array}$ & Fungos & Insetos & $\begin{array}{c}\text { Erva } \\
\text { de } \\
\text { Pass. }\end{array}$ & $\begin{array}{c}\text { Folhagem } \\
\text { rala /cor } \\
\text { anormal }\end{array}$ & $\begin{array}{c}\text { Poda } \\
\text { unilateral/ } \\
\text { drástica }\end{array}$ \\
\hline $\mathbf{0}$ & 811 & 1793 & 1040 & 1340 & 1936 & 1499 & 2205 & 1915 & 1982 \\
$\mathbf{1}$ & 790 & 323 & 562 & 731 & - & 513 & 22 & 210 & - \\
$\mathbf{2}$ & 402 & 94 & 298 & 145 & - & 156 & 3 & 63 & - \\
$\mathbf{3}$ & 180 & 18 & 244 & 10 & - & 44 & 0 & 24 & - \\
$\mathbf{4}$ & 43 & 2 & 80 & 1 & - & 6 & 0 & 13 & 154 \\
$\mathbf{5}$ & 4 & 0 & 6 & 3 & 294 & 12 & 0 & 5 & 94 \\
\hline Total & $\mathbf{2 2 3 0}$ & $\mathbf{2 2 3 0}$ & $\mathbf{2 2 3 0}$ & $\mathbf{2 2 3 0}$ & $\mathbf{2 2 3 0}$ & $\mathbf{2 2 3 0}$ & $\mathbf{2 2 3 0}$ & $\mathbf{2 2 3 0}$ & $\mathbf{2 2 3 0}$ \\
\hline
\end{tabular}

As piores notas se concentraram em fungos e podas drásticas e unilaterais, indicando assim que o cuidado na aplicação das podas é primordial para melhoria das condições dessas árvores.

TABELA 7 - Distribuição da avaliação de riscos dos parâmetros avaliados no tronco das árvores adultas de vias públicas da cidade de Nova Olímpia, PR.

\begin{tabular}{cccccccc}
\hline $\begin{array}{c}\text { Risco } \\
\text { (nota) }\end{array}$ & $\begin{array}{c}\text { Invasão } \\
\text { da } \\
\text { pista }\end{array}$ & Cavidades & $\begin{array}{c}\text { Lesões } \\
\text { da } \\
\text { Casca }\end{array}$ & $\begin{array}{c}\text { Orifícios } \\
\text { de insetos } \\
\text { (Cupins) }\end{array}$ & Fungos & Cancro & $\begin{array}{c}\text { Injúrias } \\
\text { mecânicas }\end{array}$ \\
\hline $\mathbf{0}$ & 1393 & 1151 & 781 & 1858 & 2087 & 769 & 679 \\
$\mathbf{1}$ & 564 & 545 & 739 & 220 & - & 509 & 817 \\
$\mathbf{2}$ & 173 & 225 & 301 & 93 & - & 271 & 375 \\
$\mathbf{3}$ & 79 & 169 & 187 & 26 & - & 232 & 226 \\
$\mathbf{4}$ & 15 & 86 & 135 & 14 & - & 221 & 79 \\
$\mathbf{5}$ & 6 & 54 & 87 & 19 & 143 & 228 & 54 \\
\hline Total & $\mathbf{2 2 3 0}$ & $\mathbf{2 2 3 0}$ & $\mathbf{2 2 3 0}$ & $\mathbf{2 2 3 0}$ & $\mathbf{2 2 3 0}$ & $\mathbf{2 2 3 0}$ & $\mathbf{2 2 3 0}$ \\
\hline
\end{tabular}

nos troncos das árvores analisadas. Conforme de Angelis et al. (2007), a ocorrência de cancro na arborização urbana de dois bairros em Maringá, PR, relatando que o mesmo está diretamente relacionado a pequenos atos de vandalismo que causam ferimentos como, galhos quebrados, fixação de cartazes e utilização dos troncos como local para "estacionar" bicicletas e motos. Tais ações antrópicas deixam espaços abertos para a entrada dos patógenos causadores do cancro.

TABELA 8 - Distribuição da avaliação de riscos dos parâmetros avaliados na base do tronco das árvores adultas de vias públicas da cidade de Nova Olímpia, PR.

\begin{tabular}{|c|c|c|c|c|c|c|c|c|}
\hline $\begin{array}{l}\text { Risco } \\
\text { (nota) }\end{array}$ & $\begin{array}{c}\text { Brotação } \\
\text { Epicórmica }\end{array}$ & $\begin{array}{c}\text { Lesões } \\
\text { na } \\
\text { casca }\end{array}$ & Cavidades & Fun & $\begin{array}{c}\text { Raízes } \\
\text { adventícias }\end{array}$ & $\begin{array}{c}\text { Ausência } \\
\text { de } \\
\text { Neilóide }\end{array}$ & $\begin{array}{l}\text { Raízes } \\
\text { cortadas }\end{array}$ & $\begin{array}{l}\text { Espaço } \\
\text { permeável }\end{array}$ \\
\hline
\end{tabular}




\begin{tabular}{ccccccccc}
$\mathbf{0}$ & 2159 & 1346 & 1418 & 2200 & 1548 & 1873 & 2035 & - \\
$\mathbf{1}$ & 71 & 385 & 461 & - & 418 & - & 152 & 376 \\
$\mathbf{2}$ & - & 237 & 198 & - & 144 & - & - & - \\
$\mathbf{3}$ & - & 186 & 101 & - & 80 & - & 37 & 1470 \\
$\mathbf{4}$ & - & 56 & 30 & - & 23 & - & - & - \\
$\mathbf{5}$ & - & 20 & 22 & 30 & 17 & 357 & 6 & 384 \\
\hline Total & $\mathbf{2 2 3 0}$ & $\mathbf{2 2 3 0}$ & $\mathbf{2 2 3 0}$ & $\mathbf{2 2 3 0}$ & $\mathbf{2 2 3 0}$ & $\mathbf{2 2 3 0}$ & $\mathbf{2 2 3 0}$ & $\mathbf{2 2 3 0}$ \\
\hline
\end{tabular}

Os parâmetros analisados sobre a ausência de neilóide e o espaço permeável tiveram mais notas graves em relação aos outros parâmetros avaliados na base do tronco. Estas notas evidenciam que muitos plantios realizados são feitos com covas muito profundas (ausência de neilóide) deixando as raízes em profundidade problemática para trocas gasosas e expansão.

Fica evidente também que a maioria das áreas livres (espaço permeável) de Nova Olímpia estão entre $1 \mathrm{~m}^{2}$ até $1,5 \mathrm{~m}^{2}$ e que cerca de $83 \%$ estão em tamanho não apropriado para um bom desenvolvimento das árvores. Os indivíduos com avaliação 5 são praticamente troncos que estão ocupando o espaço permeável por inteiro, e isso pode acarretar problemas sérios, pois este espaço é importante para o bom desenvolvimento fisiológico da árvore. Um espaço permeável adequado garante aeração do solo e disponibilidade de nutrientes para as plantas e esta condição contribui para uma melhor defesa da planta contra patógenos, pois uma planta saudável está menos susceptível a estes (BIONDI,1985). Bortoleto et al. (2006) verificou em Águas de São Pedro, SP que o tamanho da área livre foi determinante nos problemas de afloramento de raízes, ou seja, a situação de calçadas fissuradas em Nova Olímpia provavelmente também estará vinculada as pequenas áreas livres.

Para que fosse possível fazer comparações entre as regiões analisadas foi realizada uma distribuição em porcentagem das avaliações executadas (Figura 2) e com isso visualizar de forma mais simplificada as regiões mais afetadas. 
FIGURA 2 - Distribuição das avaliações encontradas em cada região de análise (copa, tronco e base), na população de árvores de vias públicas adultas de Nova Olímpia, PR.

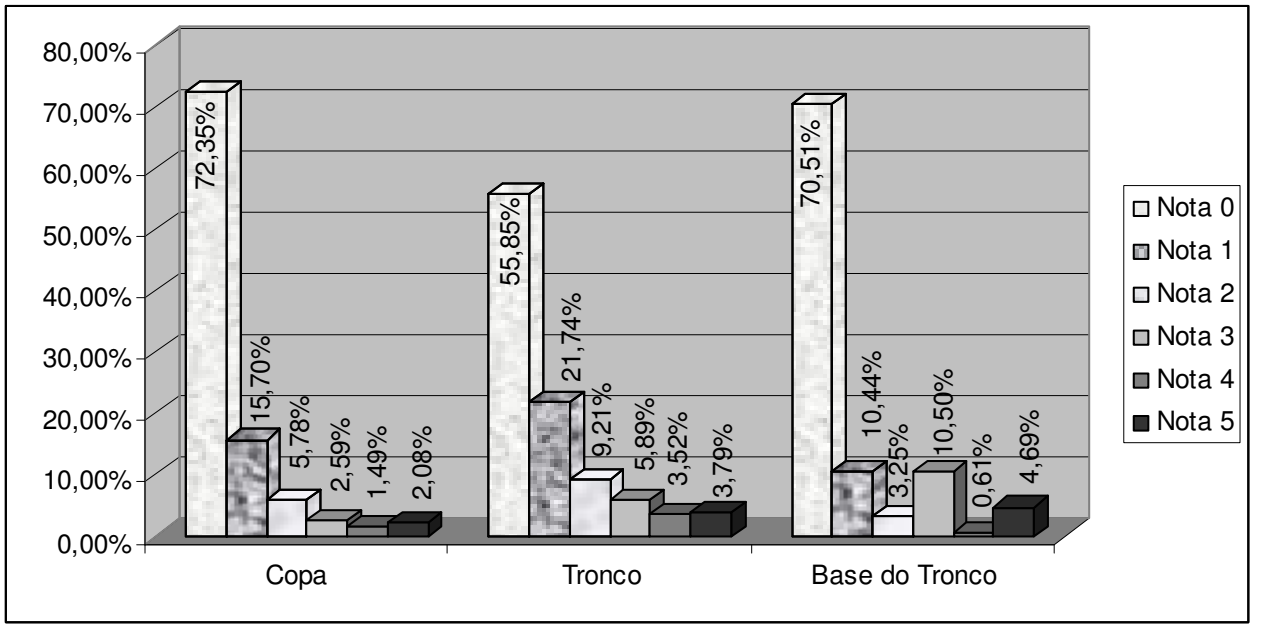

A nota mais frequente foi a zero, confirmando que existiram muitos casos, dentro dos vários parâmetros avaliados, em que não se verificou nenhuma evidência de depreciação da árvore.

Na região da copa poucos indivíduos foram classificados com notas que demonstram riscos mais elevados ( 4 e 5). Isto é um bom indicativo, pois a copa é a região mais ampla e bem desenvolvida na maioria das árvores urbanas, e também a mais utilizada pela fauna, aves principalmente, e é onde acontecem às principais atividades fenológicas das plantas. Estes resultados consolidam uma boa situação geral das copas de árvores de Nova Olímpia.

A região do tronco foi a que apresentou maior ocorrência de notas com indicação de condições gerais ruins (aumento do risco de queda e de impacto), sendo a região onde se verificou a maior freqüência de problemas mais preocupantes.

Na região da base do tronco a nota 5 se mostrou bastante elevada tendo freqüência de 4,69\%. Isso significa que esta região também apresentou quantidade preocupante de problemas sérios e sendo esta de maior influência sobre a queda de árvores, este fato se torna ainda mais agravante.

Não foram encontrados trabalhos com metodologia semelhante ao ponto de serem viáveis boas comparações entre os dados, dessa forma, a discussão não pode ser aprofundada.

\section{Análise para Índice Final (Hierarquização)}

A tabela 9 demonstra todos os riscos verificados e com os quais foi possível formular o índice final (Tabela 10) para hierarquização dos resultados.

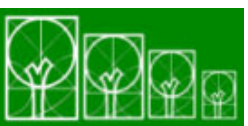


TABELA 9 - Quantidade de riscos atribuídos por árvore adulta com sua referida freqüência $(\mathrm{F})$.

\begin{tabular}{ccccccc}
\hline $\begin{array}{c}\text { Risco } \\
\text { (nota) }\end{array}$ & $\begin{array}{c}\text { Maior Risco } \\
\text { (Cond. Gerais) }\end{array}$ & $\mathbf{F ~ ( \% )}$ & $\begin{array}{c}\text { Risco Rede } \\
\text { Elétrica }\end{array}$ & $\mathbf{F ~ ( \% )}$ & $\begin{array}{c}\text { Risco Efeitos } \\
\text { Colaterais }\end{array}$ & $\mathbf{F}(\%)$ \\
\hline $\mathbf{0}$ & 0 & 0 & - & - & - & - \\
$\mathbf{1}$ & 95 & 4,26 & 1323 & 59,33 & 0 & 0 \\
$\mathbf{2}$ & 35 & 1,57 & - & - & - & - \\
$\mathbf{3}$ & 751 & 33,68 & 734 & 32,91 & 1208 & 54,17 \\
$\mathbf{4}$ & 183 & 8,21 & - & - & - & - \\
$\mathbf{5}$ & 1166 & 52,29 & 173 & 7,76 & 1022 & 45,83 \\
\hline Total & $\mathbf{2 2 3 0}$ & $\mathbf{1 0 0}$ & $\mathbf{2 2 3 0}$ & $\mathbf{1 0 0}$ & $\mathbf{2 2 3 0}$ & $\mathbf{1 0 0}$ \\
\hline
\end{tabular}

Os resultados demonstram um fator preocupante, pois $52,29 \%$ das árvores adultas analisadas receberam a nota 5 , ou seja, apresentam indicativos de problemas sérios.

Em relação aos efeitos colaterais (ruas movimentadas, ruas residenciais e ruas sem casas) ficou constatado que nenhuma árvore adulta está localizada em rua totalmente sem casas; $54,17 \%$ das árvores estão em ruas residenciais (menos movimentadas) e 45,83\% das árvores estão em ruas bem movimentadas, ou seja, com maior risco da queda de árvores atingirem pessoas.

TABELA 10 - Quantidade de árvores e a freqüência $(F)$ final para os índices finais para população de árvores adultas de Nova Olímpia, PR.

\begin{tabular}{ccc}
\hline Índice Final & Q. Árvores & $\mathbf{F}(\%)$ \\
\hline Índice de 3 até 6 - risco de menor importância & 40 & 1,79 \\
Índice de 7 até 11 - risco de média importância & 1863 & 83,54 \\
Índice de 12 até 15 - risco de elevada importância & 327 & 14,66 \\
\hline TOTAL & 2230 & 100 \\
\hline
\end{tabular}

Com os resultados dos índices finais pode-se hierarquizar tomada de decisões para manejo e, portanto conclui-se que $14,66 \%$ das árvores necessitam de ações mais emergenciais.

\section{CONCLUSÕES}

As árvores de vias públicas de Nova Olímpia, PR, possuem problemas mais graves no tronco e na base do tronco.

O índice final para hierarquização permitiu selecionar as árvores com problemas mais emergenciais. Todos os resultados e fichas cadastrais, assim como a localização das 
árvores com problemas mais sérios e prioritárias para ações de manejo foram devidamente encaminhadas à administração pública do município.

Este trabalho demonstra que é possível em um período de campo relativamente curto (3 meses) fazer um levantamento completo e já destinado a planejar o direcionamento de ações de manejo de forma hierarquizada dos riscos mais elevados para os mais baixos.

\section{REFERÊNCIAS BIBLIOGRÁFICAS}

BIONDI, D. Diagnóstico da Arborização de Ruas da Cidade de Recife. 1985. 167 f. Dissertação (Mestrado em Engenharia Florestal) -_Universidade Federal do Paraná, Curitiba, 1985.

BORTOLETO, S. Inventário Quali-quantitativo da arborização viária de Águas de São Pedro - SP. 2004. Tese (Doutorado em Agronomia) - Escola Superior de Agronomia Luiz de Queiroz, Universidade de São Paulo, Piracicaba, 2004.

BORTOLETO, S., SILVA FILHO, D. F., LIMA, A. M. L. P. Prioridades de manejo para arborização viária da Estância de Águas de São Pedro - SP, por setores. Revista da sociedade brasileira de arborização urbana, v. 1, n. 1, p. 62-73, 2006.

CASTRO, R. M. Estudo comparativo do cancro em árvores de acompanhamento viário em duas áreas distintas - Central e residencial - na cidade de Maringá-PR. Maringá, UEM, 2004. 42 p. Dissertação (Mestrado em Agronomia). Universidade Estadual de Maringá.

DE ANGELIS, B.L.D., CASTRO, R.M., DE ANGELIS NETO, G. Ocorrência do cancro de tronco em árvores de acompanhamento viário na cidade de Maringá, Paraná. Revista da sociedade brasileira de arborização urbana, v. 2, n. 2, p. 31-44, 2007.

FONSECA, F. P; CZUY, D. C. Formação do Arenito Caiuá: uso, ocupação do solo e problemas ambientais da região noroeste do Paraná. In: III SIMPÓSIO NACIONAL DE GEOGRAFIA AGRÁRIA - II SIMPÓSIO INTERNACIONAL DE GEOGRAFIA AGRÁRIA, Presidente Prudente, 2005. Anais... Presidente Prudente, 2005.

GREY, G. W.; DENEKE, F. J. Urban forestry. New York, John Wiley, 1978.

IBGE, Instituto Brasileiro de Geografia e Estatística. Planilha sobre populações residentes segundo os municípios, em 01 de abril de 2007. Disponível em: $<$ http://www.ibge.gov.br/home/estatistica/populacao/contagem2007/popmunic2007layoutT CU14112007.xls> Acesso em: 05 mai, 2009.

KÖPPEN, W. Climatologia. Com un estudio de los climas de la tierra. In: IAPAR. CARTAS CLIMÁTICAS BÁSICAS DO ESTADO DO PARANÁ, 1978, Londrina, 41p.

LIMA, A. M. L. P.; COUTO H. T. Z. do; ROXO, J.L.C. Análise das espécies mais freqüentes da arborização viária na zona urbana central do município de Piracicaba - SP. In: 
CONGRESSO BRASILEIRO DE ARBORIZAÇÃO URBANA, 2; 1994, Anais. São Luis: Sociedade Brasileira de arborização urbana, p. 555-578, 1994

MAACK, R. Geografia física do Estado do Paraná. Curitiba: BADEP, 1968. 350 p.

MOBEIG, P. Zona Pioneira do Norte do, São Paulo. Revista Geografia, v. 1, n. 2, p. 31-44, 1935.

SAMPAIO, A. C. F. Análise da arborização de vias públicas das principais zonas do plano piloto de Maringá - PR. 2006. 150p. Dissertação. (Mestrado em Geografia) Universidade Estadual de Maringá, Maringá.

SEITZ, R.A. Avaliação visual de árvores de risco (AVR). Mini-curso In: X CBAU CONGRESSO BRASILEIRO DE ARBORIZAÇÃO URBANA, Maringá, 2006. Anais... Maringá, 2006. CD-ROM.

SILVA FILHO D. F. Cadastramento informatizado, sistematização e análise da arborização das vias públicas da área urbana do município de Jaboticabal - SP, Jaboticabal, 2002. 81 p. Dissertação de mestrado - Faculdade de Ciências Agrárias e veterinárias, Universidade Estadual Paulista "_Julio de Mesquita Filho". Jaboticabal-SP, 2002

TAKAHASHI, L. T. - A Arborização Urbana e a Distribuição de Energia Elétrica em dois Bairros da Cidade: Jardim Alvorada e Zona 5. 1997 (Monografia especialista em Geografia do Estado do Paraná), Maringá, 1997.

VELOSO, H. P. GÓES-FILHO, L. Fitogeografia brasileira - classificação fisionômicoecológica da vegetação neotropical. BOLETIM TÉCNICO DO PROJETO RADAMBRASIL, Série Vegetação v. 1, p. 1-80. 1982. 